\title{
Pediatric Facial Fractures: Case Series and Critical Review \\ ORIGINAL
}

\section{Abstract}

Background: The purpose of the present study is to report twenty cases of children with facial fractures admitted to the department of Oral and Maxillofacial Surgery at Hospital da Restauração/FUSAM Recife/Brazil and review the English medical literature.

Methods and Findings: A retrospective case series study was developed. A total of 20 fractures were treated. Male was the main gender with average age of 8.7 years old. Motor vehicle accident was the main cause of injury (35\%). Mandible fracture was the most common type of fracture $(80 \%)$ and it was unilateral in $75 \%$ of cases. The sites most often affected were the symphysis (44\%) and condyle (38\%).

Conclusion: Facial fractures in pediatric patients present important repercussions of functional and aesthetics nature. The socioeconomic and environmental aspects directly influence the incidence of facial trauma in this period of life. The parental supervision directly affects the etiologic factors (fall and motor vehicle accidents) and can be used as a factor to prevent these conditions.

\section{Keywords}

Pediatric Facial Fracture, Mandible, Treatment.
David Gomes de Alencar Gondim 1,2,3,

Ricardo Viana Bessa Nogueira ${ }^{6}$, Belmiro Cavalcanti do Egito Vasconcelos ${ }^{4}$, Marcelo Fernando do Amaral ${ }^{5}$, Auremir Rocha Melo ${ }^{5}$, Ivo Cavalcante Pita-Neto 2,3, Antonio Marcos Montagner ${ }^{1}$

1 São Leopoldo Mandic Institute and Research Center, Campinas, SP, Brazil.

2 Oral and Maxillofacial Surgery Department, Hospital Regional do Cariri, Juazeiro do Norte, CE, Brazil.

3 School of Dentistry, Leão Sampaio University.

4 Professor, Department of Oral and Maxillofacial Surgery, Director, Master, PhD Programs, Department of Oral and Maxillofacial Surgery, University of Pernambuco, Recife, PE, Brazil.

5 Oral and Maxillofacial Surgery Department, Hospital de Urgência de Sergipe, Aracaju, SE, Brazil.

6 Dental School, Federal University of Alagoas, Maceió, Brazil.

\section{Contact information:}

David Gomes de Alencar Gondim.

Address: Rua Jose Vicente de Lima, n. 180 apto: 501. Cep: 63040710. Juazeiro do Norte - Ceará/Brasil.

\section{Introduction}

The maxillofacial fractures in the pediatric age group are relatively uncommon, yet they are no less important [1, 2]. Their injuries are multifactorial as a result of polytrauma and often need prolonged stay in an intensive care unit secondary to airway monitoring, the need for tracheostomy or feeding tubes [3].

The pediatric patient may be categorized according to various levels of growth and development. The correct definition of each 
stage becomes essential for a proper approach and treatment. The infant includes the newborn up to 23 months of life. Preschool is that childhood period between 2 and 5 years of age, whereas the child is defined as the period between 11 to 13 years old and. School-age is that period between 6 and 10 to 12 years old. Puberty is the period during which secondary sex characteristics develop, and adolescence is roughly from 11 to 19 years of age $[4,5]$.

Accidents whilst playing are the major causes of injury, followed by sport injuries, traffics accidents, assaults and work-related accidents [6-8]. Infanticide attempt by the mother and interpersonal violence are sporadically reported [9].

The lack of pneumatization, the considerable number of fat pads, the developing bone and mixed dentition contributes to elasticity and stability, requiring greater force to produce a fracture and reflecting its low incidence in the facial skeleton [1, 2, 6, 7, 10-12].

Many factors make the fractures in pediatric patients different to fractures in the adult. Physical examination is less accurate and they are less able to communicate their symptoms. Conventional radiography may underdiagnose these injuries and computed tomography scanning of routine with a high accuracy is advised [12, 13]. The unfavorable shape of the deciduous crown for retention of wires and splints, the bone's elasticity, the relatively small size of the face and the growth process can also influence the pattern of a fracture, its management and the postoperative period of fixation $[1,2,10]$. The ankylosis of the temporomandibular joint causing impairment of its function is more common in this age group [14] and damage to the growth of the condylar center also influences the decision for the use of a conservative approach [15].

Socioeconomic conditions also influence injuries in children as well as adults and the assessment of the etiological aspects shows the conditions prevailing in each country and period $[10,11,16]$. Furthermore, young children usually are under parental supervision and consequently less likely to be exposed to major injuries, occupational trauma or interpersonal violence that are typical features of facial fractures in adults $[17,18]$.

Due to the differences in anatomic, physiologic, and psychological development between adults and children, not only the consequences of trauma differ but also the techniques of management should be modified to address the child's particular stage of anatomic, physiologic, or psychological development [19].

The purpose of this article is to report twenty cases of maxillofacial fractures in the pediatric patient admitted to the department of Oral and Maxillofacial Surgery at Hospital da Restauração/FUSAM - Recife/Brazil and to perform a literature review to assist the clinician in the management of this unique and highly specialized area.

\section{Patients and Method}

During a period of 2 years (from February/2010 to January/2012), 20 preschool and school-age children with maxillofacial fractures were admitted at the Division of Oral and Maxillofacial Surgery in the Hospital da Restauração - Recife/Brazil. For each child the following protocol was done: (1) extraoral and intraoral clinical examination; (2) extraoral panoramic radiography; (3) CT scanning of the upper and lower jaws with 3D reconstruction.

The records of patients were studied according to the complexity of the fracture (minimal, marked and comminuted), anatomic location, cause of injury, concomitant dentoalveolar fractures as well as to age and gender.

An electronic search via the National Library of Medicine (PubMed; www.pubmed.gov) was carried out for case reports about pediatric facial fractures published among January 2002 to December 2012. The following specific medical subject headings and 
keywords were used: "(pediatric [tiab] OR child[tiab] OR neonate[tiab] OR infant[tiab] AND (maxillofacial injury[mesh] OR jaw fractures[mesh] OR mandibular fractures[mesh] OR zygomatic fractures[mesh] OR orbital fractures[mesh]".

Studies were included only if all of the following eligibility criteria were met: 1) published in English; 2) trail designed case reports; 3) age, type of radiologic examination, treatment of choice, removal of fixation's hardware and follow-up included in the case report.

About 70 articles met the criteria and all data were extracted and tabulated (figures 1, 2).

Figure 1: Pediatric facial fractures' articles by year. - TOTAL PER YEAR

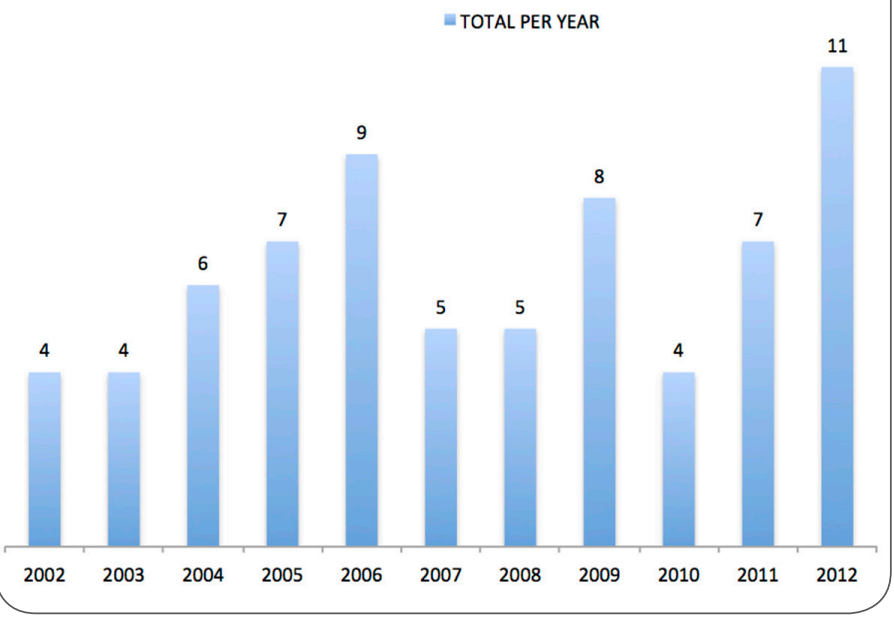

Figure 2: Cumulative graph of pediatric facial fractures' articles.
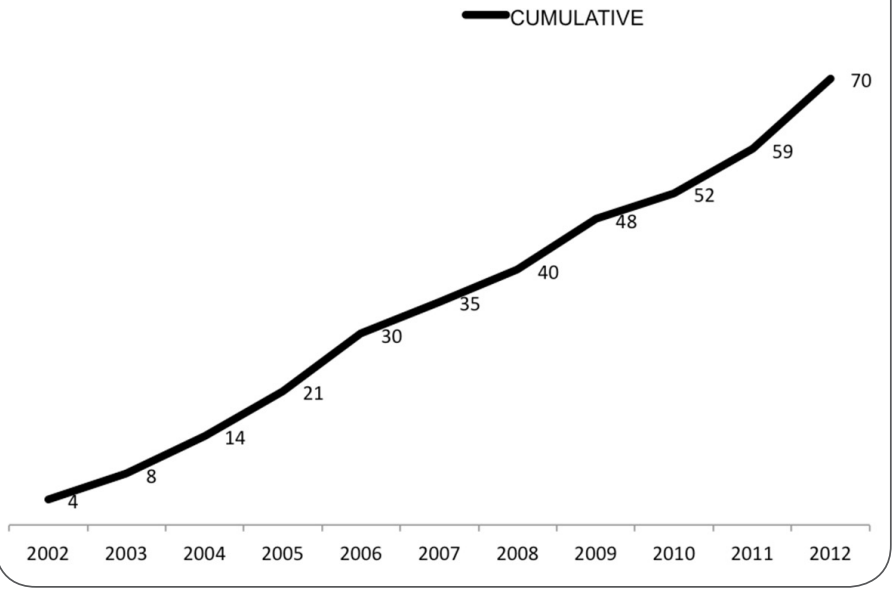

\section{Results}

The ages of twenty cases ranged from 0 to 15 years, with an average of 8.7 years old. The majority of the cases (75\%) were male. Motor vehicle accidents (35\%) was the most often mechanism of injury followed by fall injuries ( $n=4 ; 20 \%)$, cycling accidents, gunshot injuries, horse's kick, violence and others (table 1).

Mandibular fractures were the most common $(n=$ $16 ; 80 \%)$, followed by zygomatic $(n=3 ; 15 \%)$ and orbital floor fractures $(n=1 ; 5 \%)$ (table 2 ). Symphysis $(n=7 ; 44 \%)$ and condyle $(n=6 ; 38 \%)$ were the most affected sites of the mandibles fractures, followed by injuries of the body $(n=3 ; 25 \%)$ and angle ( $n=2 ; 13 \%)$ (table 3$)$. In twelve cases, the fractures were unilateral $(75 \%)$ and their complexity, in most cases ( $n=6 ; 30 \%$ ) was classified as moderate displacement. A mixed or permanent dentition was present in 16 (80\%) patients.

Surgical intervention was required in $75 \%$ of the patients with these fractures. Open reduction, non-

Table 1. Etiology of facial fractures.

\begin{tabular}{|l|c|c|}
\hline \multicolumn{1}{|c|}{ Cause } & Number of cases & $\%$ \\
\hline Fall & 4 & 20 \\
\hline Motor vehicle & 7 & 35 \\
\hline Cyclist accident & 3 & 15 \\
\hline Firearm injury & 2 & 10 \\
\hline Assault & 1 & 5 \\
\hline Animal injury & 2 & 10 \\
\hline Traumatic delivery & 1 & 5 \\
\hline Total & 20 & 100 \\
\hline
\end{tabular}

Table 2. Anatomic location of fractures.

\begin{tabular}{|l|c|c|}
\hline Anatomic Location & Number of cases & $\%$ \\
\hline Mandible & 16 & 80 \\
\hline Maxilla & 0 & 0 \\
\hline Zygomatic & 3 & 15 \\
\hline Orbital & 1 & 5 \\
\hline Total & 20 & 100 \\
\hline
\end{tabular}


Table 3. Mandible fracture's pattern.

\begin{tabular}{|l|c|c|}
\hline Mandible Anatomic Location & Number of cases & $\%$ \\
\hline Symphysis & 7 & 44 \\
\hline Parasymphysis & 1 & 6 \\
\hline Body & 4 & 25 \\
\hline Angle & 2 & 13 \\
Ramus & 0 & 0 \\
\hline Condyle & 6 & 38 \\
\hline Total & 20 & 100 \\
\hline
\end{tabular}

Figure 3: Modalities of treatment.

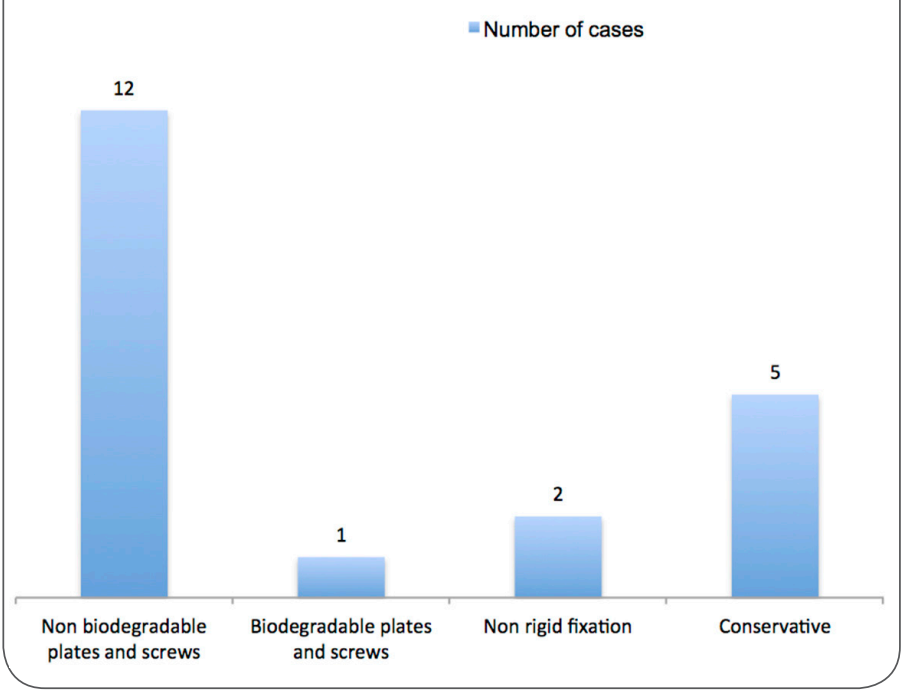

biodegradable plates and screws were the most frequent modalities of treatment $(n=12 ; 60 \%)$. The biodegradable plates were chosen for only one patient and the conservative treatment was applied in 5 occasions (25\%) (figure 3 ).

\section{Discussion}

Injury remains the leading cause of mortality of children under 14 years old, with the majority of pediatric injuries resulting from blunt trauma, much of which are preventable [6]. The incidence of facial fractures is lower in the pediatric population than in the adult age and represents $1 \%$ to $14.7 \%$ of facial fractures from general population $[10,19]$.
The reasons cited for this low incidence include the retruded position of the face relative to the "protecting" skull, face-to-head ratio volume, thicker layer of adipose tissue covering the more elastic bones, the flexibility of suture lines [10, 12] and the protected environment in which children live in leading to less exposure to the typical mechanisms of injury $[18,20]$. Further, stability is increased by the presence of tooth buds within the jaws and the lack of sinus pneumatization [10].

The median age found in this study is consistent with values reported by other studies $[6,13,18$, 20]. The incidence of facial fractures increases during puberty and adolescence due to the practice of unsupervised physical activities and sports [3]. Our sample, although reduced, highlights the fact that in half of the patients the fractures occurred as a result of bicycle or motor vehicle accidents. Such condition reiterates the increasing violence in traffic, associated with negligence of the use of protective gear (helmet and seat belt).

In this study there was a male predominance in all ages, in accordance with others [14, 21, 22], which has remained constant over time, ranging from 1.1:1 to 8.5:1. Probably associated with more violent behaviors and dangerous physical activities [10].

In the decision-making process related to the approach chosen for facial fractures in pediatric patients, factors such as age, associated trauma, fracture complexity and timing of the dentition should be considered [23]. The conservative approach, in most cases, has satisfactory results. Although this approach has not been the main mode of treatment in this study, the elevated osteogenic potential and rapid capacity of bone remodeling contribute to a predictable outcome of this therapy [12].

In fractures with dislocation associated with aesthetic and functional limitations, surgery is a suitable option [18]. In our study, we observed a higher incidence of surgical approaches ( $n=12 ; 60 \%)$ due to a pattern of comminuted and/or displaced fracture. In such situations, we attribute a narrow 
and long postoperative follow-up aiming to identify possible changes in bone growth.

Mandibular fractures are the most common facial fractures seen in hospitalized children and the condylar region is the most frequently fractured site [7]. Until mid-1970s, closed reduction and immobilization with MMF was used for all types of pediatric fractures. Nowadays, open reduction and rigid internal fixation (ORIF) has become the standard of care for management of displaced fractures [7].

When a fixation modality is required, a small titanium plating system should be placed through limited incisions to adequately expose the fracture. The hardware may then be removed 2 to 3 months after its placement [19]. Bioresorbable plate fixation in pediatric craniofacial surgery as a means of avoiding the potential and well-documented problems with rigid metal fixation has been used recently with good results [13]. This technology was not available in the studied hospital.

Condylar fractures without malocclusion present satisfactory results with the use of a conservative approach. The high remodeling and osteogenic potential of the immature skeleton justify this treatment modality. Those fractures with occlusal changes, require a short immobilization period (1 week) in order to avoid ankylosis in the temporomandibular joint (TMJ), plus an early mobilization and instructions for jaw exercises [1, 12].

With relation to fractures involving the zygomatic complex, the treatment is conservative for cases of greenstick fractures, minimally displaced fractures and without aesthetic or functional impairment [19]. The 03 cases found in our study showed significant displacement (02 cases) or functional impairment (01 case) justifying the choice for an open reduction and internal fixation.

The facial trauma in pediatric patients is a pathology that, when neglected, causes aesthetic, functional and psychological disorders [6]. Although it has not received its due importance by the Pu- blic Power, especially in developing countries, the literature shows its relevance in the form of steady growth in the number of publications.

\section{Conclusion}

Facial fractures in pediatric patients present important repercussions of functional and aesthetics nature. A careful physical examination associated with a proper imaginologic study assist in the diagnosis formulation and rapid decision-making, given the early process of bone healing in this age group. Although the conservative treatment is effective in most cases, when surgical approach is indicated, a functionally stable fixation is advised as well as the consideration of issues related to bone growth and the presence of dental germs. The socioeconomic and environmental aspects directly influence the incidence of facial trauma in this period of life. The parental supervision directly affects the etiologic factors (fall and motor vehicle accidents) and can be used as a factor to prevent these conditions.

\section{References}

1. Oji C. Fractures of the facial skeleton in children: a survey of patients under the age of 11 years. J Craniomaxillofac Surg. 1998; 26(5): 322-5. Epub 1998/11/20. PubMed PMID: 9819684.

2. Shaikh ZS, Worrall SF. Epidemiology of facial trauma in a sample of patients aged 1-18 years. Injury. 2002; 33(8): 669-71. Epub 2002/09/06. doi: S0020138301002017 [pii]. PubMed PMID: 12213416.

3. Vyas RM, Dickinson BP, Wasson KL, Roostaeian J, Bradley JP. Pediatric facial fractures: current national incidence, distribution, and health care resource use. J Craniofac Surg. 2008; 19(2): 339-49; discussion 50. Epub 2008/03/26. doi: 10.1097/ SCS.0b013e31814fb5e3. 00001665-200803000-00010 [pii]. PubMed PMID: 18362709.

4. Anderson DM. Dorland's illustrated medical dictionary. 28th ed. ed. Philadelphia: WB Saunders; 1994. 10 p.

5. Spraycar M. Physician's desk reference medical dictionary. 1st ed ed. Baltimore: Williams and Wilkins; 1995. 1 p.

6. Gassner R, Tuli T, Hachl O, Moreira R, Ulmer H. Craniomaxillofacial trauma in children: a review of 3,385 cases with 6,060 injuries in 10 years. J Oral Maxillofac Surg. 2004; 62(4): 399-407. Epub 2004/04/16. doi: S0278239103012576 [pii]. PubMed PMID: 15085503 . 
7. Zimmermann CE, Troulis MJ, Kaban LB. Pediatric facial fractures: recent advances in prevention, diagnosis and management. Int J Oral Maxillofac Surg. 2005; 34(8): 823-33. Epub 2005/09/13. doi: S0901-5027(05)00224-9 [pii] 10.1016/j.ijom.2005.06.015. PubMed PMID: 16154722

8. Qing-Bin Z, Zhao-Qiang Z, Dan C, Yan Z. Epidemiology of maxillofacial injury in children under 15 years of age in southern China. Oral Surg Oral Med Oral Pathol Oral Radiol. 2013; 115(4): 436-41. doi: 10.1016/j.0000.2012.04.026. PubMed PMID: 22940023.

9. Serel S, Can Z, Ersoy A, Sen Z. Management of mandibular fracture using open reduction and internal fixation in a neonate: case report. J Oral Maxillofac Surg. 2005; 63(3): 3969. Epub 2005/03/03. doi: S0278239104015290 [pii] 10.1016/j. joms.2004.06.058. PubMed PMID: 15742294.

10. Kaban LB, Mulliken JB, Murray JE. Facial fractures in children: an analysis of 122 fractures in 109 patients. Plast Reconstr Surg. 1977; 59(1): 15-20. Epub 1977/01/01. PubMed PMID: 831236.

11. lida S, Matsuya T. Paediatric maxillofacial fractures: their aetiological characters and fracture patterns. J Craniomaxillofac Surg. 2002; 30(4): 237-41. Epub 2002/09/17. doi: S1010518202902957 [pii]. PubMed PMID: 12231205.

12. Hatef DA, Cole PD, Hollier LH, Jr. Contemporary management of pediatric facial trauma. Curr Opin Otolaryngol Head Neck Surg. 2009; 17(4): 308-14. doi: 10.1097/MOO.0b013e32832d95a0. PubMed PMID: 19528801.

13. Ferreira PC, Amarante JM, Silva AC, Pereira JM, Cardoso MA, Rodrigues JM. Etiology and patterns of pediatric mandibular fractures in Portugal: a retrospective study of 10 years. J Craniofac Surg. 2004; 15(3): 384-91. Epub 2004/04/28. doi: 00001665-200405000-00008 [pii]. PubMed PMID: 15111795.

14. Adekeye EO. Pediatric fractures of the facial skeleton: a survey of 85 cases from Kaduna, Nigeria. J Oral Surg. 1980; 38(5): $355-$ 8. Epub 1980/05/01. PubMed PMID: 6928934

15. Tabrizi R, Langner NJ, Zamiri B, Aliabadi E, Daneste $H$, Naghizade S. Comparison of nonsurgical treatment options in pediatric condylar fractures: rigid intermaxillary fixation versus using guiding elastic therapy. J Craniofac Surg. 2013; 24(3): e203-6. doi: 10.1097/SCS.0b013e318293d605. PubMed PMID: 23714959

16. Munante-Cardenas JL, Olate S, Asprino L, de Albergaria Barbosa $J R$, de Moraes M, Moreira RW. Pattern and treatment of facial trauma in pediatric and adolescent patients. J Craniofac Surg. 2011; 22(4): 1251-5. doi: 10.1097/SCS.0b013e31821c696c. PubMed PMID: 21772206.

17. Zerfowski M, Bremerich A. Facial trauma in children and adolescents. Clin Oral Investig. 1998; 2(3): 120-4. Epub 1999/02/03. PubMed PMID: 9927912.

18. Smith DM, Bykowski MR, Cray JJ, Naran S, Rottgers SA, Shakir S, et al. 215 mandible fractures in 120 children: demographics, treatment, outcomes, and early growth data. Plast Reconstr Surg. 2013; 131(6): 1348-58. doi: 10.1097/PRS.0b013e31828bd503. PubMed PMID: 23714795
19. Haug RH, Foss J. Maxillofacial injuries in the pediatric patient. Oral Surg Oral Med Oral Pathol Oral Radiol Endod. 2000; 90(2): 126-34. Epub 2000/08/11. doi: S1079-2104(00)85852-7 [pii]. 10.1067/moe.2000.107974. PubMed PMID: 10936829.

20. Ferreira PC, Amarante JM, Silva PN, Rodrigues JM, Choupina $M P$, Silva $A C$, et al. Retrospective study of 1251 maxillofacial fractures in children and adolescents. Plast Reconstr Surg. 2005; 115(6): 1500-8. Epub 2005/04/30. doi: 00006534-20050500000006 [pii]. PubMed PMID: 15861052.

21. Acton CH, Nixon JW, Clark RC. Bicycle riding and oral/ maxillofacial trauma in young children. Med J Aust. 1996; 165(5): 249-51. Epub 1996/09/02. PubMed PMID: 8816680.

22. Adams CD, Januszkiewcz JS, Judson J. Changing patterns of severe craniomaxillofacial trauma in Auckland over eight years. Aust N Z J Surg. 2000; 70(6): 401-4. Epub 2000/06/08. PubMed PMID: 10843392.

23. Zimmermann CE, Troulis MJ, Kaban LB. Pediatric facial fractures: recent advances in prevention, diagnosis and management. Int J Oral Maxillofac Surg. 2006; 35(1): 2-13. PubMed PMID: 16425444

\section{Comment on this article:}

\section{8 in $8+\mathbf{S} P$}

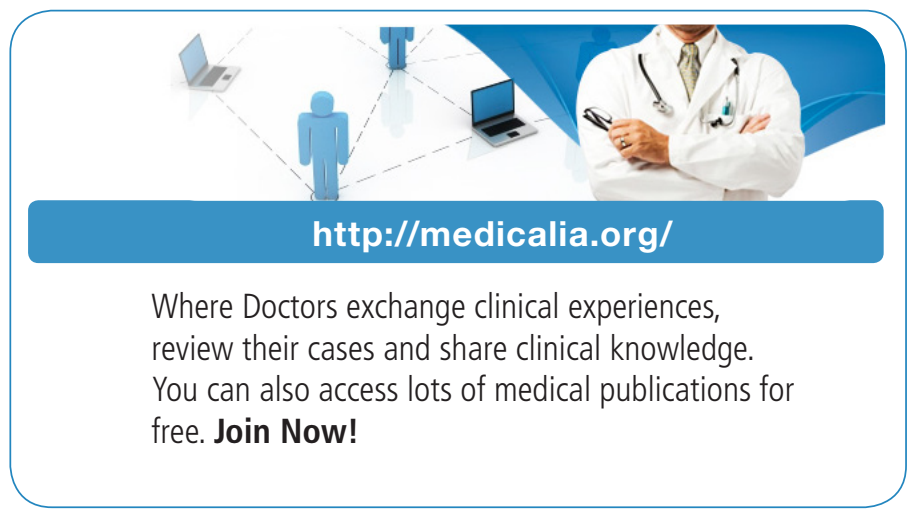

\section{Publish with iMedPub}

\section{http://www.imed.pub}

International Archives of Medicine is an open access journal publishing articles encompassing all aspects of medical science and clinical practice. IAM is considered a megajournal with independent sections on all areas of medicine. IAM is a really international journal with authors and board members from all around the world. The journal is widely indexed and classified Q1 in category Medicine. 